\title{
The need and means for evidence-based medicine in developing countries
}

The frustrations expressed by the practitioner in the following scenario are echoed by thousands of healthcare providers who attend to the millions of patients in developing countries all over the world. The problems are depressing, and even for our sympathetic colleagues from the developed world, it may be difficult to understand the cynicism and desperation. This editorial attempts to answer 3 important questions on the relevance of evidence-based medicine for developing countries by drawing from experience in the Philippine setting.

\section{Scenario}

You are a facilitator conducting an evidence-based medicine workshop for a group of rural practitioners in a remote barrio in the Philippines. Suddenly, an exasperated participant breaks his silence. "All of this science sounds really good, doctor, but I practice in a small town where I see very poor patients. We don't have computers and medical libraries, you know. In fact, we sometimes don't even have electricity. How relevant can evidence-based medicine be in our setting?" A tension-filled pause follows as you sit still, eyes downcast, trying to prepare a reply. What would be your response?

DO WE REALLY NEED EVIDENCE-BASED MEDICINE IN DEVELOPING COUNTRIES?

\section{Limited resources}

In many developing countries, the bulk of healthcare expenditures continues to be shouldered by individual patients or their families. Thus, nothing could be more appalling than a physician ordering unnecessary tests or prescribing inappropriate treatments for indigent patients. However, throughout the Philippines, for example, resting electrocardiograms (ECGs) are routinely done in asymptomatic patients to screen for coronary artery disease (CAD). The test costs approximately US\$5, enough to provide 3 full meals for a family of 5. A careful appraisal of the evidence would have revealed to practitioners that resting ECGs are virtually useless as a screening instrument for $\mathrm{CAD}{ }^{1}$

As this example illustrates, the practice of evidence-based medicine in developing countries could save millions of dollars in health expenses, with the ultimate beneficiary being neither the government nor the physicians but the patients themselves, who could then spend their hard earned money on more immediate needs, such as food, shelter, and education.

\section{Limited capacity for drug regulation}

Because of limited resources, departments of health often falter in their role as regulators of the pharmaceutical industry. Approval of a drug for marketing becomes so easy that drugstores are flooded with myriad products, often listed for questionable indications. A survey in 1994 showed, for example, that as many as $50 \%$ of Filipino patients with acute myocardial infarction received a class of drugs called "metabolic enhancers" for which no evidence of efficacy exists. ${ }^{2}$ Evidence-based medicine could prepare physicians to battle this onslaught of false claims in defense of the patients for whom they care.

\section{Limited capacity for continuing medical education}

In the Philippines and in many other developing countries, drug companies invest heavily in continuing medical education (CME).

Many medical societies and academic institutions are so poor that "scientific meetings" would not be possible without the support of industry. On the surface, this relation may seem innocent. In reality, however, this situation has given the pharmaceutical industry nearly total control of the direction and content of the scientific sessions and has dulled the distinction between CME and drug promotion.

In 1996, for example, despite medical evidence favoring the use of $\beta$-blockers over calcium channel blockers for hypertension, a local survey showed that only $17 \%$ of hypertensive patients received $\beta$-blockers, whereas $62 \%$ received the more expensive calcium antagonists. ${ }^{3}$ Such a phenomenon is probably because of successful marketing activities.

HOW DO WE OVERCOME OBSTACLES TO PRACTISING EVIDENCE-BASED MEDICINE IN DEVELOPING COUNTRIES? Limited access to literature databases

How can one track the literature for answers to specific problems when facilities for conducting an efficient search do not exist? Considering the benefits that can be attained, the budgetary requirements for electronic access aren't that steep. A basic desktop computer with internet access can cost as little as US\$900. This investment would be worthwhile for any healthcare facility (provided there is electricity to run it). Convincing administrative heads to invest in such equipment entails looking for opportunities to publicly cite how efficient database searches help us in our daily lives-to prepare lectures and research protocols and to manage difficult patient problems in our practices. Before long, unfamiliarity with literature databases leads to curiosity, then to enthusiasm, and finally to purchase orders.

Another option we have used is to find a well meaning drug company willing to make small investments for purely altruistic reasons. At the very least, requests for such computers are more productive than requests for dinners, outings, or other frivolous needs of physicians. If all these approaches fail, other methods of practicing evidence-based medicine can be used (see below).

\section{Limited access to adequate library facilities}

After conducting an exhaustive search for evidence, nothing is more frustrating than a trip to a library with near empty shelves. Rather than wallow in self pity, however, a group of evidence-based medicine practitioners in our country developed a "literature retrieval algorithm" that harnessed the strengths of various possible sources of published literature. In this algorithm, attempts to retrieve articles move in sequence from the top 3 libraries in the country, to libraries of multinational drug companies, and finally to friends or colleagues in other countries who have access to their own library facilities. Thus far, the system seems to work quite well, with retrieval rates of over $80 \%$. Fortunately, we have not lost many friends in the process. 
Questionable applicability of journal articles that are eventually retrieved

What assurance do practitioners have that a treatment that worked in a developed country will work as well in their rural environment? The tempting answer is that we can never be sure unless we duplicate all of these studies in all settings. It may seem obvious that this is next to impossible, and yet numerous studies have been proposed in our institution that were based on such a suggestion.

In the case of trials on effectiveness, the issue of applicability is being addressed on several fronts. ${ }^{45}$ Aside from helping clinicians to decide if a trial result is applicable to a particular patient, the criteria we have developed on applicability will help researchers to decide exactly when these trials should be replicated. ${ }^{5}$

HOW DO WE OVERCOME OBSTACLES TO TEACHING EVIDENCE-BASED MEDICINE IN DEVELOPING COUNTRIES? The obstacles to applying evidence-based medicine also get in the way of teaching it. We gathered the following list of problems and practical solutions while conducting evidence-based medicine workshops throughout the Philippines.

\section{Inexperience in small group learning}

Small group, problem based learning has been the core of workshops in evidence-based medicine in many countries. ${ }^{6}$ Because of limited resources, most medical schools stick to traditional methods of didactic teaching done in large classrooms. As a result, our typical workshop participant is a reserved individual, unaccustomed to spontaneous public discussions, and evidence-based medicine facilitators can easily break into elaborate discourses in the middle of a small group discussion. In our experience, when given enough time and exposure, facilitators and participants get the hang of things. The result has always been an enjoyable and fruitful interaction that brings fresh insights into the practice of evidence-based medicine in developing countries.

\section{Lack of time to attend workshops}

One of the major problems we have encountered while conducting our evidence-based medicine workshops is lack of time, especially for Filipino physicians whose major source of income is from their daily private clinics. As a result, we have modified these workshops into 1 or 2 day affairs. Critical appraisal workshops for diagnosis and treatment are interspersed with short lectures. Participants are also given the opportunity to solve clinical scenarios through hands-on literature searches, formulation of a patient related decision, and finally, presentation of a critically appraised topic (CAT). Although the shortening of workshops offers less in terms of content, it has allowed us to offer them to more participants-even the busiest of practicing clinicians.
Lack of role models for practicing evidence-based medicine An initial problem in teaching evidence-based medicine was the lack of role models who could demonstrate various strategies of implementation. As our group of evidence-based medicine practitioners grew, however, several role models emerged. Some of them are using actual patient problems as a stimulus for educational prescriptions and the generation of CATs. For example, an experimental evidence-based medicine service was recently formed in the Department of Internal Medicine of the Philippine General Hospital. This service is attempting to create a model for the practice of evidence-based medicine in developing countries.

On another front, a group of evidence-based medicine practitioners have modelled the use of evidence-based medicine skills by asking challenging questions whenever claims of effectiveness are encountered. This approach may be used when attending a lecture at an annual convention or when encountering pharmaceutical representatives in the hospital corridor. In our opinion, these questions, raised in public, have had an effect on the quality of information being disseminated. One irate lecturer was overheard saying, "It's getting very difficult to lecture these days; the audiences seem to be asking more difficult questions."

\section{Summary}

The desperate health situation in developing countries tends to trivialise evidence-based medicine as just another western innovation-highly advanced, extremely expensive, and totally useless. We propose, however, that it is exactly this desperate situation that justifies the need for evidence-based medicine. Most of the obstacles to teaching and applying evidence-based medicine in developing countries that we have identified are daunting, but none are insurmountable. For the sake of their patients, practitioners in these areas need to come up with their own creative solutions.

\section{Resolution of the scenario}

Answers fly by your consciousness, and time seems to come to a standstill. As the tension mounts, you gather all your resources and draw on your extensive experience as an evidence-based medicine facilitator. You muster all your self control to shed your usual role as a lecturer, and with great courage you reply, "So, what do you think?"

\section{ANTONIO L DANS, MD, MSc FONIL A F DANS, MD, MSc University of the Philippines-College of Medicine Manila, Philippines}

1 Dans AL. Philippine Journal of Cardiology 1991;20:609-17.

2 Dans AL, Jara RB, Lopez M, et al, for the ISIP Study Group. Asian Heart Journal 1999;7:1-6.

3 Sison JA, Abelardo NS, Atabug J, et al. Asian Heart Journal 1994;2:29-32.

4 Dans AL, Dans LF, Guyatt GH, et al JAMA 1998;279:545-9.

5 Glasziou P, Guyatt GH, Dans AL, et al. ACP J Club 1998;129:A15-6.

6 Sackett DL, Straus SE, Richardson WS, et al. Evidence-based medicine. How to practice and teach EBM. 2nd edition. New York: Churchill Livingstone, 2000 